\title{
ЗНАЧИМОСТЬ АУТОАНТИТЕЛ ПРИ ИНСУЛИНЗАВИСИМОМ САХАРНОМ ДИАБЕТЕ
}

\author{
Гюндуз Ахмед оглы Ахмедов*
}

Азербайджанский медииинский университет, г. Баку, Азербайджан

Поступила 20.12.2016; принята в печать 10.02.2017.

Реферат

DOI: 10.17750/КМJ2017-519

Цель. Изучение взаимосвязи между уровнями аутоантител GAD 65, IA-2 и C-пептида с генотипами человеческих лейкоцитарных антигенов DRB1_1 и DRB1_2 и наличием кетоацидоза у детей с впервые выявленным сахарным диабетом в азербайджанской популяции.

Методы. Были обследованы 128 детей с впервые выявленным сахарным диабетом. Средний возраст детей

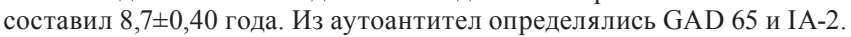

Результаты. В ходе работы не было выявлено корреляционной зависимости уровней аутоантител GAD 65 c IA-2 (r=0,067, p=0,46). Также не обнаружена корреляционная взаимосвязь уровня аутоантител GAD 65 с концентрацией C-пептида $(\mathrm{r}=+0,025, \mathrm{p}=0,011)$. Сравнение у 106 детей уровней аутоантител, HLA DRB1_1 и DRB1_2 также не выявило закономерности. В то же время между содержанием глюкозы крови и показателями GAD 65 была выявлена прямая корреляция ( $\mathrm{r}=+0,21, \mathrm{p}=0,02)$. У детей без кетоацидоза, но с высокими показателями IA-2 $(\mathrm{n}=9)$, установлена обратная корреляция между показателем IA-2 и уровнем гликозилированного гемоглобина в крови $(\mathrm{r}=-0,79, \mathrm{p}<0,05)$. У детей с тяжёлым кетоацидозом (n=9), имеющих уровень аутоантител IA-2 и GAD 65 выше нормы, выявлена обратная корреляция между уровнем глюкозы в крови $(\mathrm{r}=-0,67, \mathrm{p}<0,05)$ и указанными аутоантителами $(\mathrm{r}=-0,72, \mathrm{p}<0,05)$. Дети с высокими показателями IA-2 в крови (n=9) имели прямую корреляционную взаимосвязь между этим показателем и уровнем $\mathrm{C}$-пептида $(\mathrm{r}=+0,75, \mathrm{p}<0,05)$.

Вывод. В ходе работы не было установлено взаимосвязи между уровнями аутоантител GAD 65 и IA-2 у детей с сахарным диабетом и кетоацидозом.

Ключевые слова: сахарный диабет, дети, аутоантитела.

\section{UTILITY OF AUTOANTIBODIES IN INSULIN-DEPENDENT DIABETES MELLITUS}

G.A. Akhmedov

Azerbaijan Medical University, Baku, Azerbaijan

Aim. To study relationship of levels of autoantibodies GAD 65, IA-2 and C-peptide with DRB1_1 and DRB1_2 genotypes of human leukocyte antigen and presence of ketoacidosis in children with newly diagnosed diabetes mellitus among the population of Azerbaijan.

Methods. 128 children with newly diagnosed diabetes mellitus were examined. The average age of children was $8.7 \pm 0.40$ years. GAD 65 and IA-2 autoantibodies were measured.

Results. During the study no correlation between concentration of autoantibodies GAD 65 and IA-2 was found $(\mathrm{r}=0.067, \mathrm{p}=0.46)$. Also no correlation was revealed between GAD 65 autoantibodies and C-peptide concentration $(\mathrm{r}=+0.025, \mathrm{p}=0.011)$. Comparison of HLA DRB1_1 and DRB1_2 autoantibodies in 106 children also demonstrated no correlation. At the same time, positive correlation was found between glucose level and GAD $65(\mathrm{r}=+0.21, \mathrm{p}=0.02)$. In children without ketoacidosis, but with high IA-2 $(n=9)$ negative correlation with $\mathrm{HbA}_{1 \mathrm{c}}$ level in the blood was revealed $(r=-0.79, p<0.05)$. Children with severe ketoacidosis $(n=9)$ with the level of IA-2 and GAD 65 autoantibodies above normal, inverse correlation between the level of blood glucose $(\mathrm{r}=-0.67, \mathrm{p}<0.05)$ and mentioned autoantibodies $(\mathrm{r}=-0.72, \mathrm{p}<0.05)$ was revealed. Children with high IA-2 in the blood $(\mathrm{n}=9)$ had a positive correlation of this parameter with the level of C-peptide $(r=+0.75, \mathrm{p}<0.05)$.

Conclusion. The study found no correlation between the levels of GAD 65 and IA-2 autoantibodies in children with diabetes mellitus and ketoacidosis.

Keywords: diabetes mellitus, children, autoantibodies.

Выявление в крови аутоантител к $\beta$-клеткам островков Лангерганса поджелудочной железы напрямую ассоциируется с возникновением инсулинзависимого сахарного диабета [1]. Обнаружение какого-либо аутоантитела служит маркёром повреждения $\beta$-клеток. Сложность диагностического процесса связана с наличием различных вариантов фенотипа заболевания. При этом аутоантитела могут выявляться и при инсулиннезависимом сахарном диабете [2].

С увеличением количества видов аутоантител возрастает и риск возникновения

Адрес для переписки: nauchnayastatya@yandex.ru сахарного диабета [3]. Наиболее критическим периодом для возникновения этого заболевания у детей считают возраст от 1 до 5 лет. Именно в этом возрасте отмечают высокий титр аутоантител в крови [4]. Одновременное выявление у ребёнка других диабетогенных аллелей человеческого лейкоцитарного антигена (HLA), наличие инсулинзависимого сахарного диабета в семье ещё больше увеличивают этот риск [5].

В деструкции поджелудочной железы значительную роль играют аутоантитела IA-2. В одном из исследований был проведён сравнительный анализ больных, имеющих высокий и низкий уровни IA-2, при 
этом у последних сахарный диабет носил прогрессирующий характер. Было установлено, что с нарастанием титра аутоантител IA-2 увеличивается количество случаев возникновения сахарного диабета [6].

Инсулинзависимый сахарный диабет также ассоциируется с аутоантителами GAD 65. Их можно выявить в крови детей за несколько лет до манифестации заболевания. Если у инсулиннезависимых больных сахарным диабетом в крови выявлены аутоантитела GAD 65, мы имеем дело с диабетом типа 1,5 , или аутоиммунным латентным сахарным диабетом взрослых [7].

У группы больных в ходе изучения взаимосвязи между аутоантителами GAD 65, IA-2, HLA DRB1_1 и HLA DRB1_2 была выявлена статистическая значимая взаимосвязь наличия HLA DRB1_1 и DRB1_2 с уровнем аутоантител IA-2 [8].

Цель исследования - изучение взаимосвязи между уровнями аутоантител GAD 65, IA-2 и C-пептида с генотипами человеческих лейкоцитарных антигенов DRB1_1 и DRB1_2 и наличием кетоацидоза у детей с впервые выявленным сахарным диабетом в азербайджанской популяции.

Были обследованы 128 детей с впервые выявленным сахарным диабетом. Средний возраст детей составил $8,7 \pm 0,40$ года. В исследовании участвовали больные, поступившие в детскую клиническую больницу №6 г. Баку и во 2-е педиатрическое отделение терапевтической клиники Азербайджанского медицинского университета. Диагноз «инсулинзависимый сахарный диабет» был установлен в соответствии с рекомендациями «Международного общества по сахарному диабету у детей и подростков» (ISPAD - от англ. International Society for Pediatric and Adolescent. Diabetes) на основании определения в крови уровня аутоантител GAD 65 и IA-2. Аутоантитела IA-2 и GAD 65 определяли иммуноферментным методом на иммуноферментном планшетном анализаторе (Awareness Technology Inc., США) и анализаторе ChemWell 2910 (Awareness Technology Inc., США).

Согласно рекомендациям ISPAD, диагностика аутоиммунного диабета у детей основана именно на определении данных аутоантител. Другие аутоантитела [к островкам Лангерганса (ICA), инсулину (IAA), транспортёру цинка 8 (ZnT8Ab)] могут быть определены дополнительно, в ка520 честве вспомогательных аутоантител ввиду того, что их клиническая значимость незначительна. Аутоантитела GAD 65 выявляют у 70-80\% больных, аутоантитела IA-2 — у $60 \%$, а другие аутоантитела при наличии сахарного диабета обнаруживают в более редких случаях [7]. Генетические исследования HLA DRB1_1 и DRB1_2 проводили в Оклендском научно-исследовательском институте, расположенном в штате Калифорния Соединённых Штатов Америки.

Статистические вычисления проведены с использованием статистической программы Statistica 13.0 (Dell Software, 2016).

Средняя концентрация глюкозы в капиллярной крови у больных была $405 \pm 13,55$ мг/дл, средний показатель гликозилированного гемоглобина $\left(\mathrm{HbA}_{1 \mathrm{c}}\right)-$ $12,1 \pm 0,15 \%$. Из числа обследованных соотношение мальчиков и девочек составило $46,8 \%(\mathrm{n}=60)$ и 53,2\% $(\mathrm{n}=68)$ соответственно. 44,5\% детей поступили в стационар в состоянии кетоацидоза.

В ходе изучения у больных не было выявлено корреляционной взаимосвязи между уровнями аутоантител GAD 65 и IA-2 $(\mathrm{r}=0,067, \mathrm{p}=0,46)$. Корреляция также не обнаружена между аутоантителами GAD 65 и $\mathrm{C}$-пептидом $(\mathrm{r}=+0,025, \mathrm{p}=0,11)$.

Одновременно с этим у 106 детей было проведено изучение взаимосвязи между уровнем аутоантител GAD 65, IA-2, HLA DRB1_1 и HLA DRB1_2. Корреляционной зависимости между этими показателями не установлено.

У 55,4\% пациентов $(n=71)$ уровень GAD 65 был выше нормы, у 44,5\% (n=57) ниже. Уровень аутоантител IA-2 выше нормального показателя имели 39,8\% (n=51) детей, у 60,2\% (n=77) он был ниже нормы, у $14,5 \%(n=19)$ больных не выявлено никаких аутоантител.

Наряду с этим исследовали взаимосвязь между уровнем аутоантител и концентрацией $\mathrm{HbA}_{1 \mathrm{c}}$. Между уровнем $\mathrm{HbA}_{1 \mathrm{c}}$ и показателями аутоантител GAD 65 и IA-2 $(n=128)$ взаимосвязи не обнаружено. В то же время между уровнем глюкозы и показателями GAD 65 была выявлена прямая корреляция $(\mathrm{r}=+0,21, \mathrm{p}=0,02)$.

Проведено сравнение уровня этих аутоантител у детей, поступивших в состоянии кетоацидоза и без него (табл. 1). Выявлено, что у 8,2\% $(n=9)$ из 110 детей уровни аутоантител GAD 65 и IA-2 были высокими. 
Показатели аутоантител GAD 65 и IA-2 (ME/мл) у больных сахарным диабетом с кетоацидозом и без него

\begin{tabular}{|l|c|c|c|c|c|}
\hline \multicolumn{1}{|c|}{ Показатели } & № & M & Min & Мах & $\begin{array}{c}\text { Стандартное } \\
\text { отклонение }\end{array}$ \\
\hline IA-2, кетоацидо3 - & 12 & 365,96 & 59,8 & 555,7 & 219,05 \\
\hline GAD 65, кетоацидо3 - & 12 & 238,62 & 80,2 & 498,8 & 110,14 \\
\hline IA-2, кетоацидо3 + & 9 & 260,36 & 38,5 & 547,6 & 171,44 \\
\hline GAD 65, кетоацидо3 + & 9 & 296,45 & 73,1 & 533,2 & 185,84 \\
\hline
\end{tabular}

У 10,9\% (n=12) детей, несмотря на высокое содержание аутоантител GAD 65 и IA-2, кетоацидоза не было. Разница между этими показателями не имела статистической значимости ( $>0,05)$.

У детей без кетоацидоза, но с высокими показателями IA-2 (n=9) была выявлена обратная корреляция между содержанием IA-2 и уровнем $\mathrm{HbA}_{1 \mathrm{c}}$ в крови $(\mathrm{r}=-0,79$, $\mathrm{p}<0,05)$.

У детей с тяжёлым кетоацидозом (n=9), у которых уровень аутоантител IA-2 и GAD 65 был выше нормы, установлена прямая корреляция между концентрацией глюкозы в крови $(\mathrm{r}=-0,67, \mathrm{p}<0,05)$ и содержанием указанных антител $(\mathrm{r}=-0,72, \mathrm{p}<0,05)$.

У детей с высокими показателями IA-2 в крови $(\mathrm{n}=9)$ была выявлена прямая корреляционная взаимосвязь между уровнем этого аутоантитела и содержанием $\mathrm{C}$-пептида $(\mathrm{r}=+0,75, \mathrm{p}<0,05)$.

\section{ВЫВОД}

Не установлено взаимосвязи между уровнями аутоантител IA-2 и GAD у детей с сахарным диабетом и кетоацидозом.

\section{ЛИТЕРАТУРА}

1. Brorsson C.A., Onengut S., Chen W.M. et al. Type 1 diabetes genetics consortium. Novel association between immune-mediated susceptibility loci and persistent autoantibody positivity in type 1 diabetes. Diabetes. 2015; 64 (8): 3017-3027. DOI: 10.2337/db14-1730.

2. Pihoker C., Gilliam L.K., Hampe C.S., Lernmark A. Autoantibodies in diabetes. Diabetes. 2005; 54 (2): S52-S61. DOI: 10.2337/diabetes.54.suppl_2.S52.

3. Gullstrand C.I., Wahlberg J., Ilonen J. et al Progression to type 1 diabetes and autoantibody positivity in relation to HLA-risk genotypes in children participating in the ABIS study. Pediatr. Diabetes. 2008; 9: 182-190. DOI: 10.1111/j.1399-5448.2008.00369.x.

4. Horie I., Kawasaki E., Shimomura A. et al. Emergence of anti-islet autoantibodies in Japanese patients with type 1 diabetes. Endocr. J. 2010; 57 (7): 623-628. DOI: 10.1507/ endocrj.K10E-068.

5. Bonifacio E. Predicting type 1 diabetes using biomarkers. Diabetes Care. 2015; 38 (6): 989-996. DOI: 10.2337/dc15-0101.

6. Siljander H., Härkönen T., Hermann R. et al Role of insulin autoantibody affinity as a predictive marker for type 1 diabetes in young children with HLA-conferred disease susceptibility. Diabetes Metab. Res. Rev. 2009; 25 (7): 615-622. DOI: 10.1002/dmrr.998.

7. Uibo R., Lernmark A. GAD65 autoimmunity-clinical studies. Adv. Immunol. 2008; 100: 39-78. DOI: 10.1016/ S0065-2776(08)00803-1.

8. Qu H.Q., Polychronakos C. The effect of the MHC locus on autoantibodies in type 1 diabetes. J. Med. Genet. 2009; 46 (7): 469-471. DOI: 10.1136/jmg.2009.066647.

УДК 616.9: 616.36-002.1: 616.36-002.2

\section{ХАРАКТЕРИСТИКА ВИРУСНОГО ГЕПАТИТА А НА ФОНЕ ХРОНИЧЕСКОГО ВИРУСНОГО ГЕПАТИТА В}

Анастасия Дмитриевна Бушманова ${ }^{1,2 *}$, Анастасия Александровна Сухорук ${ }^{1,2}$, Надежда Всеволодовна Иванова 2, Елена Владимировна Эсауленко ${ }^{1,2}$

${ }^{1}$ Санкт-Петербургский государственный педиатрический медицинский университет, г. Санкт-Петербург, Россия;

${ }_{2}^{2}$ Научно-исследовательский институт эпидемиологии и микробиологии им. Пастера, 2. Санкт-Петербург, Россия

Поступила 24.03.2017; принята в печать 28.04.2017.

Реферат

DOI: 10.17750/KMJ2017-521

Цель. Охарактеризовать клинические проявления вирусного гепатита А на фоне хронического вирусного гепатита В.

Методы. Исследование проведено за период 2012-2015 гг. в СПБ ГБУз «Клиническая инфекционная больница им. С.П. Боткина». Методом случайной выборки выполнен ретроспективный анализ 259 медицинских карт стационарного больного с диагнозом «гепатит А». Этиология заболевания подтверждена обнаружением маркёров к вирусам гепатитов А, В и С методом иммуноферментного анализа.

Результаты. Этиологическая структура гепатита А-микст: сочетание гепатит A + хронический вирусный ге-

Адрес для переписки: nastya1089@mail.ru 